\title{
She Came, She Saw, She Sowed: Re-negotiating Gender-Responsive Priorities for Effective Development of Agricultural Biotechnology in Sub-Saharan Africa
}

\author{
Obidimma C. Ezezika • Jennifer Deadman • \\ Abdallah S. Daar
}

Accepted: 4 April 2012/ Published online: 27 April 2012

(C) The Author(s) 2012. This article is published with open access at Springerlink.com

\begin{abstract}
In this paper, we argue for the importance of incorporating a gendered perspective for the effective development of sustainable agricultural biotechnology systems in sub-Saharan Africa. Priority setting for agricultural policy and project development requires attention to gender issues specific to the demands of agricultural biotechnology. This is essential for successfully addressing food security and poverty reduction in sub-Saharan Africa (SSA). There has been a great deal of debate and literature on the implications of gender in agricultural development and policy. However, the implications of gender in agricultural biotechnology and have received relatively less attention, especially in SSA. Based on interviews with key stakeholders in agricultural biotechnology across SSA, review of pertinent literature and field observations, we have found that incorporating a gendered perspective is critical for the sustainable development of agricultural biotechnology and requires attention in five areas: the inclusion of women, particularly women farmers, in decision-making around biotech/genetically modified (GM) crop and trait selection; equal representation of women as men in education for agricultural science and in agricultural biotechnology research and development professions; greater involvement of women in extension services and farmers' associations for successful delivery of information about biotech crops equality between men and women in access to resources for biotech/GM crop cultivation; and increased control for
\end{abstract}

Electronic supplementary material The online version of this article (doi:

10.1007/s10806-012-9396-9) contains supplementary material, which is available to authorized users.

O. C. Ezezika (ه) · J. Deadman · A. S. Daar

Sandra Rotman Centre, 101 College Street East, Suite 406, Toronto, ON M5G 1L7, Canada

e-mail: obidimma.ezezika@srcglobal.org; ezezika@gmail.com

J. Deadman

e-mail: jennifer.deadman@srcglobal.org

A. S. Daar

e-mail: a.daar@utoronto.ca 
women farmers over biotech/GM crop management and income generation. We explain the consequences of failing to include such gender-responsive considerations into priority setting for agricultural biotechnology development and policy in SSA and provide recommendations for how policy makers and project partners of development initiatives can avoid such oversights.

Keywords Gender - Agriculture $\cdot$ Biotechnology $\cdot$ Sub-Saharan Africa

\section{Introduction}

Incorporating a gendered perspective into priority setting for agricultural biotechnology policy and project development is essential for effectively addressing food security and poverty reduction in sub-Saharan Africa (SSA). With the advent of, and increased investment in, agricultural biotechnology in developing countries in the past one and a half decades (James 2011), the conditions in which agricultural practices are exercised have changed and the stakes for achieving beneficial impacts of the technology have heightened.

Contesting viewpoints on the value and impact of such technologies in developing regions are abundant and well-documented. From appreciation of advancements made in the field and support for continued and increased use for reasons such as higher yield, improved food quality, and drought and insect resistance (Azadi and Ho 2010), to expressed concern and protest about perceived negative effects of the technologies, including health and environmental impacts (Krattinger and Potrykus 2007), preservation of traditional farming practices (Shilla et al. 2008; Weale 2010), contradiction with religious and cultural beliefs, and skepticism of private sector involvement (Ezezika et al. 2012; Weale 2010), the issues surrounding acceptance of agricultural biotechnology have been widely studied and discussed.

Throughout this ongoing debate, the use of agricultural biotechnology to address food security and poverty reduction in developing regions such as SSA continues, and we are faced with an evolving context in which to understand how best to manage the implementation of such initiatives. Development of appropriate policy for the use of agricultural biotechnology in developing countries (Mechlem 2010) and consideration of the distinct set of factors that will affect the transition of agricultural biotechnology products from stages of development to impactful use must be addressed (Ezezika et al. 2012).

Gender is one of these important factors that must be considered for ensuring that the growing use of biotech crops is managed effectively and that the benefits of the technology are experienced by those most in need. Agricultural systems in SSA currently favor male-centric perspectives on crop production and management, despite the fact that 60-80\% (Food and Agricultural Organization of the United Nations 2011) of the agricultural labor carried out in this sector is performed by women. This inequitable division of labor between women and men in crop agriculture in SSA and other developing regions of the world has been well explored for the past three decades (World Bank 2009). We must turn our attention 
to gender-responsive priority-setting to address the impacts of agricultural biotechnology policy and development projects on women and men in agriculture and the impacts that women and men can have on agricultural biotechnology development.

Unfortunately, policy makers and project partners in the development of biotech/ genetically modified (GM) crops often downplay or disregard the centrality of gender to the effectiveness of such development initiatives in SSA. Reform is needed in priority setting of policy and development projects in ways that reflect the needs, experience, and expertise of women and men in the agricultural sector in SSA, and in light of the changing conditions and prospects for their work, as presented in this paper. Agricultural biotechnology initiatives provide avenues through which we can assess and re-negotiate the inequitable social structures and social relations at play in the agricultural sector in SSA and other developing regions. We have identified five key areas for gender-responsive action, pertinent to the changing context and demands of agricultural biotechnology initiatives in SSA, and highlighted how gender issues in such areas differ from those of traditional agriculture. The five key areas include: decision-making around crop and trait selection; inclusion in agricultural biotechnology research and development; representation in extension services and farmers' associations; access to resources for crop adoption and cultivation; and control over post-harvest crop and income management.

\section{Gender in Agriculture}

Research in the arena of gender and agriculture has been vast, encompassing gender-based inequalities and differences in socio-political and socio-economic status of women in developing countries (World Bank 2009). The role of gender has been considered in the area of health biotechnologies (Singh et al. 2009) as well, but, to our knowledge, has not been given adequate attention in the area of agricultural biotechnology. Incorporating a gendered perspective into priority setting has been identified as important for mainstreaming gender in agricultural systems (Meizen-Dick 2010; World Bank 2009) and for improving women's contribution to agricultural production and sustainability (IAASTD 2009). The absence of consideration for gender issues in agricultural policies (Pellizzoli 2010), institutional structures for access to capital and bargaining power (Mohamed 2003; Mpuga 2010; Nina and Sanders 1998) and social norms around appropriate gender roles in division of labor, decision-making, and access to resources and education (Gotschi et al. 2009; Nation 2010; Kleinbooi and Lahiff 2007; Federici 2011; Hyder 2005; Katungi et al. 2008; Oya and Sender 2009) have been well documented. The impact on women's health (Doss 2001; Loewenson et al. 2010), economic stability (Peterman 2011), and food production (Alene et al. 2008) have also been given considerable attention. In addition to and within these gender-related areas of concern, there exist unique circumstances, presented here, which are associated with the advent of agricultural biotechnology in advancing agricultural systems in SSA, that require gender-responsive priority setting. 
Drawing on examples from agricultural biotechnology initiatives in SSA and other developing regions, we explain here the potential benefits of setting genderresponsive priorities in these five areas for agricultural biotechnology systems and the impact on sustainable food production and poverty reduction. We provide recommendations for where gender-responsive priorities should be set by policy makers and project partners in development initiatives.

The context in which this study has taken place and from which these areas of consideration have emerged is specific to agricultural biotechnology. Overlap exists between some areas presented here and the vast research conducted on gender and agriculture which is covered briefly below. Unique circumstances come into play when discussing agricultural biotechnology, including increased investment in development initiatives in the sector, presence of private companies, and greater risk to the potential benefits of the technology reaching those most in need. This context of agricultural biotechnology makes imperative the necessity to, and provides opportunities for, re-assessing the gender-responsive needs in the agricultural sector in SSA, understanding how best to address these needs through gender-responsive priority setting in policy and development initiatives, and an avenue through which to do so.

\section{Decision-Making Regarding Crop and Trait Selection}

In 2010, the World Bank deemed women's knowledge of agricultural requirements in developing nations, including those in SSA, as necessary for determining effective methods for resource management and adaptation in agriculture (World Bank 2009). However, as found in the report, and in our interviews, at present, women farmers are rarely consulted in decision-making for agricultural biotechnology development, despite their vast knowledge of farming systems. Incorporation of women farmers' expertise into crop and trait selection is rare, though their preferences weigh heavily on the acceptance and uptake of biotech/GM crops. One stakeholder from Kenya involved in communications for biotech/GM crops commented on his mother's preference for cultivating and cooking with traditional lines of maize: "She has a plot of maize where she plants that very old maize... it is the traditional one with no good lines... she still believes that when she wants to make Uji (porridge), it makes very nice Uji. Whether that is true or not, I don't know. But you will not convince her otherwise."

Instead, men and large-scale private companies partnered in agricultural biotechnology projects handle most of the primary decision-making and priority setting for crop and trait selection in agricultural biotechnology in SSA, and such decisions tend to reflect the needs of the private companies and their commercial farmers in developed countries. One stakeholder from a National Research Institute in Uganda commented on the disconnect between the role women have as primary laborers in agriculture and their limited presence at farmers' meetings and subsequent decision-making for agricultural biotechnology use: “...culturally, it is the women who till the land. They do most of the work. But... when you have meetings to tell people about the new technologies it is the men who turn up." 
Concern for the lack of voice women farmers have in the decision-making process was also expressed by a woman farmer in South Africa who manages a group of farmers that grow Bacillus thuringiensis $(\mathrm{Bt})$ maize crops. She stated, "When we are with men, if I put my suggestion, they don't want to take it. They [men] want their own. We've got to listen to them, we mustn't say anything. If, maybe, we [women] can come together and share our views, then we can... [have a voice]."

There is a need for the inclusion of both women and men in decision-making processes to ensure that the specific needs of both groups are taken into account as priorities are set (World Bank 2009; Meizen-Dick 2010). Consulting women and men farmers prior to the establishment of agricultural biotechnology project goals and objectives regarding crop and trait selection is essential for allowing farmers to set priorities for the projects in ways that reflect their specific needs and those of their land. This is currently underway in a gender-sensitive plant breeding initiative lead by a partnership between the Consultative Group on International Agricultural Research (CGIAR) Participatory Research on Gender Analysis (PRGA) Program and the Pan-Africa Bean Research Alliance by the International Centre for Tropical Agriculture (PABRA-CIAT). The leaders of the initiative are assessing and considering crop variety preferences of women and men, in diverse contexts, in Kenya, Rwanda, and Malawi (Biermayr et al. 2010).

\section{Inclusion in Agricultural Biotechnology Research and Development}

The inclusion of women in decision-making on technical aspects of agricultural biotechnology initiatives is also lagging. According to some people we have interviewed in the agricultural sector, this is attributed to low representation of women in higher education in agriculture, and, subsequently, few women in agricultural biotechnology research and development (R\&D) positions. According to Beintema and Di Marcantonio (2009), women make up approximately $25 \%$ of researchers in the developing world, with the lowest proportion found in Africa and the Middle East. This is incongruent with the increasing number of women attaining higher education in science and technology (Beintema and Di Marcantonio 2009, 2010), and fails to provide diversity of insight (Meizen-Dick 2010) and consideration of gender-specific needs assessment (World Bank 2009) for gender-responsive decision-making and priority setting in agricultural biotechnology initiatives.

Low representation of women in agricultural biotechnology $R \& D$ means that women are being excluded from the initial stages of project development, an important decision-making phase in which gender-specific needs can be prioritized and the groundwork for effective development initiatives established. Funding agencies and existing agricultural biotechnology projects must build the capacity of women researchers in the area of agricultural biotechnology in SSA and actively recruit women educated in science and technology into professional agricultural biotechnology R\&D positions. As stated in a report on gender in agriculture by the World Bank (2009), "If women are to benefit from modern agricultural technologies, they need to participate in research and development. Participation will permit them to set their own priorities based on their appraisal of their own needs" (World Bank 2009). 


\section{Representation in Extension Services and Farmers' Associations}

When speaking with farmers and other stakeholders in the agricultural sector, we have observed that women are underrepresented in extension services, as leaders in farmers' associations, and in ownership and management of seed companies. The representation of women in leadership roles of such organizations is critical for establishing an interface between the farmers and the providers and educators of biotech/GM crops.

The probability of an extension worker being a woman in SSA is quite low, which is inconsistent with the number of women farming in the region. As extension services are of paramount importance for the successful production of agricultural biotechnology crops-given the specific training required for the cultivation of improved varieties-representation of women in extension services can have important implications for greater reach and more effective information sharing to women farmers, thus improving the potential beneficial impact of the technology on farmers and their yields.

From our discussions with farmers, and as reported by Meizen-Dick (2010), female extension service personnel are more likely to reach women farmers. One farmer commented on the personal connection that can be made between two female agricultural experts (farmer and extension worker) and how this can ease the interaction between the two, allowing for a greater number of meetings and improved communication regarding important information about agricultural biotechnology products.

It was also suggested by a stakeholder that low representation of women in extension services may be attributable to the low participation of women educated in agricultural sciences in SSA. Though the number of women in agricultural professions has been on the rise, it has not kept up to pace with the increasing number of women attaining higher education (Beintema and Di Marcantonio 2009), which can affect the representation of women in extension work.

One farmer expressed her interest in taking on a leadership role in a farmers' association and becoming an extension worker for agricultural biotechnology to educate both women and men farmers and non-farmers based on her knowledge and experience with agricultural biotechnology products. She stated, “...I want to demonstrate [the GM technology] so they [men] can know about it. Women and [seed companies], they must do some workshops so that people can understand what is good and what is not."

To involve women in the agricultural extension service sector, for better information sharing of information to and among women farmers, incentives for women to pursue careers in agricultural extension services for agricultural biotechnology must be established by agricultural biotechnology project partners and policy makers. Encouraging women to attain higher education in agricultural sciences in pursuit of extension work will also be necessary. Providing opportunities and training for women farmers to take on extension roles for agricultural biotechnology would be effective, as well, given the connections between women farmers and their expertise and experience with the technologies. 


\section{Access to Resources Necessary for Biotech/GM Crop Adoption and Cultivation}

Lack of access to a variety of agricultural resources impedes the quality of benefits that farmers receive from biotechnology development initiatives; it negates their potential for increased production and economic stability. Research has found that women farmers are more prone than their male farmer counterparts to be negatively affected by a lack of access to affordable seed, land tenure, labor support, equipment, extension services (Meizen-Dick 2010; Doss and Morris 2001), and collateral and loans for start up and maintenance of agricultural enterprises (Ouma and De Groote 2006). When meeting with women farmers working with agricultural biotechnology crops in SSA, it was made clear that these resources are essential, the demand is high, and that the greater the women farmers' access to these resources, the greater the contribution they can make toward food sustainability and poverty reduction efforts in SSA. As one farmer stated, "If the government can organize women, and tell them that I want to give you a land to come and do farming, there will never be poverty in this country."

One major barrier to women farmers acquiring needed resources for agricultural biotechnology crop cultivation is affordability. Improved seed varieties and complementary inputs are most often unaffordable to small-scale women farmers in SSA (Ouma and De Groote 2006), due to premiums placed by private developers and distributors on improved varieties, and women's limited capacity in SSA to acquire capital or access credit to purchase higher-priced seeds and inputs. In a case study by Doss (2001), adoption of improved maize varieties and chemical fertilizer were found to be unequal for women and men, due to differential access to complementary inputs-particularly, land, labor, and extension services. It was concluded that policy measures to ensure equitable access to complementary inputs are necessary for ensuring adequate adoption of biotech crops for both women and men (Doss and Morris 2001).

We agree that policy makers and agricultural biotechnology project partners must create agricultural systems in SSA in which women farmers are afforded equal opportunities as men to access the necessary inputs for effective agricultural biotechnology crop cultivation. Credit groups and seed transfer networks for women farmers are a good starting point. They have been found to help improve the economic status of women farmers when cultivating improved cowpea varieties in Nigeria, for example (Tipilda et al. 2008).

\section{Control Over Post-harvest Management and Income Generation}

Women farmers in SSA receive fewer monetary benefits from their crops than men farmers, due to two main factors: their appointment to subsistence agriculture rather than cash crops (World Bank 2009) and the limited control they have over their products during and post production (Manda and Mvumi 2010). Women most often experience low returns on their investment of time, materials, and energy in agriculture, due to their lack of control over the type, management, and sales of the crops they produce. 
Subsistence agriculture generally generates food crops for farmers' families and local communities. The return on such crops is minimal in comparison to cash crops, which are generally sold in larger volume and exported internationally for higher prices. When involved in the cultivation of cash crops, such as Bt cotton, women have been found to be primarily responsible for harvesting the crop, while men attend to pesticide management and post-harvest sales. We found this inequality in gender roles present in our visits to Bt cotton farms at Sapouy, $120 \mathrm{~km}$ from the capital city in Burkina Faso. While both men and women were found to be involved in the cultivation of Bt cotton, women were primarily responsible for harvesting the crop, with little to no control over post-harvest sales or income. Similar circumstances were found by Subramanian et al. (2010) regarding Bt cotton cultivation in India, where women held primary responsibility for crop harvests. Though women were not involved in post-harvest management of Bt cotton in India, in comparison to conventional cotton cultivation, their involvement in harvesting was found to generate higher income and more employment, particularly for those women working as hired labor (versus home labor). Additionally, decreased male labor, due to reduced pesticide application for Bt cotton, was found to redistribute home labor, providing women farmers with greater opportunities for economic gains (Subramanian et al. 2010).

Crops produced by women farmers are also often managed post-production, in the market by male heads of households, leaving women with little control over the crops they produce and without the full financial benefits gained by men farmers. This was found in the case of women farmers in Zimbabwe, who managed postharvest grain sales mid-season, while the male heads of their households managed sales at the beginning of the storage season-a more profitable period (Manda and Mvumi 2010). Removing women from the post-harvest management of the crops they harvest also removes their control over the prevention of post-harvest losses, the result of which can dramatically impact market sales and income generation for both women and men farmers.

Agricultural biotechnology has the potential to provide women farmers with the means to obtain higher yields and improved income. However, should priority not be placed on securing women's roles in the distribution and sales market of the biotech/GM crops, and ensuring their involvement in post-harvest management practices, the desired benefits of food security and poverty reduction for those most in need-women farmers-will not be achieved. Systems established by private companies in collaboration with national agricultural research systems (NARS) to ensure that women farmers' voices are heard in post-harvest management practices, and that they receive market value for their biotech/GM crops, are necessary.

\section{Conclusion}

A gendered perspective in priority setting for agricultural biotechnology policies and projects is central to ensuring appropriate development of agricultural systems in SSA that can adequately address food security and poverty reduction. The inequalities that exist between women and men in the agricultural arena, and the 
limitations they present to the potential women have as agricultural experts in the development of agricultural biotechnology initiatives, must be acknowledged and incorporated into reform of how priorities are set in agricultural policy and project planning. Through our literature review, observations, and interviews with stakeholders in the field of agricultural biotechnology, we have identified five key areas for such action: the inclusion of women, particularly women farmers, in decisionmaking around biotech/GM crop and trait selection; recruitment of women and men in education for agricultural science and in agricultural biotechnology research and development professions; greater representation of women in extension services and farmers' associations for successful delivery of information about agricultural biotechnologies; equality between men and women in access to resources for biotech/GM crop adoption and cultivation; and increased control for women farmers over biotech/GM crop management and income generation, post-harvest.

\section{Recommendations}

We recommend the following to policy makers and private and public partners of agricultural biotechnology development projects for setting the stage for gender-responsive priority setting in agriculture.

1. Biotech/GM crop development projects (including funding agencies and private seed companies) should include small-scale women and men farmers, in SSA, in crop and trait selection prior to the establishment of project goals and objectives. The interests of multi-national companies, commercial farmers, and male-centric perspectives must not be at the forefront of the agenda, to ensure that project priorities incorporate the preferences and specific needs of the small-scale farmers, and provide value to them to ensure effective use of the technology.

2. Funding agencies, existing agricultural biotechnology projects, local research institutions, universities, and biotechnology development projects should continue to build capacity for women in science and technology education through active recruitment and provision of opportunities. Agricultural biotechnology development projects should also actively recruit those already educated in science and technology to R\&D professions, and into agricultural biotechnology development initiatives, to address gender-specific needs on the technical side of agricultural biotechnology development. Participation of women in the formative R\&D phases of agricultural biotechnology policy and project development is essential for a gender-responsive approach to ensuring involvement in priority setting and decision-making.

3. Agricultural biotechnology projects, funding agencies, and universities should establish incentives for women to pursue leadership roles in knowledge sharing on agricultural biotechnology through extension work and leadership in farmers' associations. Womens' perspectives on agricultural biotechnology must be represented and their vested interests, agricultural expertise, and connections with other women farmers must be leveraged. Provision of incentives, through higher education in agricultural sciences and programs for women farmers to take on extension roles for agricultural biotechnology and be equally represented and exert influence in farmers' associations, are needed.

4. Policy makers, agricultural biotechnology projects, and funding institutions should provide systems for affordable and accessible resources needed for successful crop cultivation. For example, the establishment of credit groups for small-scale women farmers to share resources and establish capital would be beneficial to improve the economic status of women farmers and establish gender equality with men farmers.

5. Private companies with NARS must establish priorities to ensure women farmers maintain control over their crop choices and post-harvest management practices, and receive market value for their improved production with the use of agricultural biotechnology. This will provide women with the means to obtain higher yields and improved income. 
Should consideration not be made for gender issues in the five key areas discussed above, priority setting for agricultural biotechnology policy and development projects in SSA will be missing essential elements to ensure their effectiveness and sustainability. Priorities will be absent of gender-responsive insight, and consideration of gender-specific needs for appropriate adoption, implementation, and sustainability of agricultural biotechnology, and the proposed benefits of agricultural biotechnologies for addressing food insecurity and poverty reduction will not be realized. These gender-responsive considerations may also be applicable to agricultural biotechnology initiatives in other developing regions, though further fieldwork must be carried out to incorporate on-the-ground accounts of gender and agricultural biotechnology into priority setting.

The five key areas for gender-responsive priority setting for agricultural biotechnology must be reassessed in terms of equitability and impact on the individuals, the agricultural sector in SSA, and the communities they serve. Incorporation of the viewpoints and expertise of those most affected and knowledgeable about agriculture in SSA-women farmers-will be instrumental for making appropriate and sustainable decisions for setting gender responsive priorities in agricultural policy and development initiatives.

Acknowledgments We would like to thank the anonymous reviewers of an earlier version of this paper for their helpful comments. The research carried out for this article was funded by the Bill \& Melinda Gates Foundation and supported by the Sandra Rotman Centre, ${ }^{1}$ at the University Health Network and University of Toronto. The findings and conclusions contained within are those of the authors and do not necessarily reflect official positions or policies of the Foundation.

Open Access This article is distributed under the terms of the Creative Commons Attribution License which permits any use, distribution, and reproduction in any medium, provided the original author(s) and the source are credited.

\section{References}

Alene, A. D., Manyong, V. M., Omanya, G. O., et al. (2008). Economic efficiency and supply response of women as farm managers: Comparative evidence from Western Kenya. World Development, 36, 1247-1260.

Azadi, H., \& Ho, P. (2010). Genetically modified and organic crops in developing countries: A review of options for food security. Biotechnology Advances, 28, 160-161, 168.

Beintema, N. M., \& Di Marcantonio, F. (2009). Women's participation in agricultural research and higher education: Key trends in sub-Saharan Africa, IFPRI and CGIAR Gender and Diversity Program Brief.

Beintema, N. M. \& Di Marcantonio, F. (2010). Female participation in african agricultural research and higher education: New insights, IFPRI Discussion Paper 00957.

Biermayr, P., Manners, G., Garcia, C. X., \& Cardona, A. (2010). High priority: Climate change and food security participatory research and gendered analysis program (PRGA).

Doss, C. R. (2001). Designing agricultural technology for african women farmers: Lessons from 25 years of experience. World Development, 29, 2075-2092.

Doss, C. R., \& Morris, M. L. (2001). How does gender affect the adoption of agricultural innovations? Agricultural Economics, 25, 27-39.

\footnotetext{
${ }^{1}$ Previously the McLaughlin-Rotman Centre for Global Health at the University Health Network and University of Toronto.
} 
Ezezika, O. C., Daar, A. S., Barber, K., Mabeya, J., Thomas, F., Deadman, J., et al. (2012). Factors affecting agbiotech adoption in sub-Saharan Africa. Nature Biotechnology, 30, 38-40.

FAO. (2011). The State of Food and Agriculture: Women in Agriculture. Rome.

Federici, S. (2011). Women, land struggles, and the reconstruction of the commons. WorkingUSA, 14, 41-56.

Gotschi, E., Njuki, J., \& Delve, R. (2009). Equal numbers, equal chances? A case study of gender differences in the distribution of social capital in smallholder farmer groups in Bu'zi District, Mozambique. European Journal of Development Research, 21, 264-282.

Hyder, A. A. (2005). The pervasive triad of food security, gender inequity and women's health: Exploratory research from sub-Saharan Africa. African Health Sciences, 5, 328-334.

IAASTD. (2009). International assessment of agricultural knowledge, science, and technology for development: Synthesis report: Agriculture at a crossroads. Washington.

James, C. (2011). Global status of commercialized biotech/GM Crops: 2011. ISAAA Brief No. 39. ISAAA Brief No. 43.

Katungi, E., Edmeades, S., \& Smale, M. (2008). Gender, social capital and information exchange in rural Uganda. Journal of International Development, 20, 35-52.

Kleinbooi, K., \& Lahiff, E. (2007). "Die man is die hoof en vat voor": Women's attitudes to land and farming in the communal areas of Namaqualand. Journal of Arid Environments, 70, 799-817.

Krattinger, A., \& Potrykus, I. (2007). Golden rice: A product-development partnership in agricultural biotechnology and humanitarian licensing. In A. Krattinger, R. T. Mahoney, \& L. Nelsen (Eds.), Golden rice: A product-development partnership in agricultural biotechnology and humanitarian licensing. Davis, USA: PIPRA.

Loewenson, R., Nolen, L. B., \& Wamala, S. (2010). Globalisation and women's health in Sub-Saharan Africa: Would paying attention to women's occupational roles improve nutritional outcomes? Scandinavian Journal of Public Health, 38, 6-17.

Manda, J., \& Mvumi, B. (2010). Gender relations in household grain storage management and marketing: The case of Binga District, Zimbabwe. Agriculture and Human Values, 27, 85-103.

Mechlem, K. (2010). Agricultural biotechnologies, transgenic crops and the poor: Opportunities and challenges. Human Rights Law Review, 10, 749-764.

Meizen-Dick, R., et al. (2010). Engendering agricultural research. IFPRI Discussion Paper 00973.

Mohamed, K. (2003). Access to formal and quasi-formal credit by smallholder farmers and artisanal fishermen: A case of Zanzibar 3.6.

Mpuga, P. (2010). Constraints in access to and demand for rural credit: Evidence from Uganda. African Development Review, 22, 115-148.

Nation, M. (2010). Understanding women's participation in irrigated agriculture: A case study from Senegal. Agriculture and Human Values, 27, 163-176.

Nina, L., \& Sanders, J. H. (1998). Welfare impacts of technological change on women in southern Mali. Agricultural Economics, 19, 73-79.

Ouma, J. O., De Groote, H., \& Owuor, G. (2006). Determinants of improved maize seed and fertilizer use in Kenya: Policy implications. CIMMYT.

Oya, C., \& Sender, J. (2009). Divorced, separated, and widowed women workers in rural mozambique. Feminist Economics, 15, 1-31.

Pellizzoli, R. (2010). 'Green revolution' for whom? Women's access to and use of land in the Mozambique Chókwè irrigation scheme. Review of African Political Economy, 37, 213-220.

Peterman, A. (2011). Women's property rights and gendered policies: Implications for women's longterm welfare in rural Tanzania. Journal of Development Studies, 47, 1-30.

Shilla, O., Ismail, F. A. R., \& Hauser, T. P. (2008). Controlled hybridization between wild and cultivated cotton species. In J. M. Nzuma (Ed.), Proceedings of the 1st All Africa Congress on Biotechnology. Nairobi, Kenya.

Singh, J. A., Bandewar, S., \& Singer, P. A. (2009). Sex, gender, and health biotechnology: Points to consider. BMC International Health and Human Rights, 9, 1-5.

Subramanian, A., Kirwan, K., Pink, D., \& Qaim, M. (2010). GM crops and gender issues. Nature Biotechnology, 28, 404-406.

Tipilda, A., Alene, A., \& Manyong, V. M. (2008). Engaging with cultural practices in ways that benefit women in northern Nigeria. Development in Practice, 18, 551-563.

Weale, A. (2010). Ethical arguments relevant to the use of GM crops. New Biotechnology, 27, 582-587.

World Bank. (2009). Gender in agriculture sourcebook: Agriculture and rural development series. World Bank Publications: Washington. 